\title{
Editorial: Surveillance and Mobilities.
}

\author{
Colin J. Bennett1 and Prisc illa M. Regan²
}

\begin{abstract}
The editorial introduces the pieces in this special issue on surveillance and mobilities. It draws out the key themes of the issue, asking: what is meant by 'mobility' and why it deserves such a focus; what are the goals and purposes of the surveillance of mobilities; and finally, what are the consequences. It proposes a simple typology of mobilities: 'what moves' (body, transactions, and artefacts); and 'movement itself'.
\end{abstract}

\section{Introduction}

The fourth issue of Surveillance and Society examines the themes, contexts, and questions related to surveillance and mobilities. Prior issues have explored general questions of surveillance as well as specific contexts in which surveillance occurs, e.g. the workplace. Not surprisingly many of the themes identified in the earlier issues are found in the articles in this issue as well. As was true in issue two, the 'significance of everyday surveillance' and the roles of public and private organizations are once again important in understanding and analyzing surveillance and mobilities. The writings of Michel Foucault, referenced in all earlier issues and the theme of the third issue, provide theoretical richness to the articles in this issue. Following a brief summary of the articles, we will discuss a number of common themes and trends in the articles and in surveillance studies more generally.

The issue features seven full-length articles and an artistic submission. Adam Arvidsson examines how market research has adjusted itself to the increasingly mobile consumer. Rather than assuming consumer behavior to be a situated activity, market research has come to regard all consumer actions and movements, or as he says 'life itself', as having value. This ubiquitous information gathering is found in both the online and offline worlds. His article is especially interesting in that he explicitly takes an historical approach, exploring how and why market research became interested in mobility beginning in the 1920s - what he terms the 'pre-history of the panoptic sort'. Arvidsson's concludes that the disappearance of a boundary between life and capital challenges the traditional Marxian concept of the end of capitalism and the value of labour. This article provides an interesting backdrop for the next two articles which investigate

\footnotetext{
${ }^{1}$ Department of Political Science, University of Victoria, Canada. mailto:cjb@uvic.ca

2 Department of Public \& International Affairs, George Mason University, USA. mailto:pregan@ gmu.edu
} 
aspects of surveillance in the context of air travel.

In the post-9/11 world airports and airline passengers, which well represent the mobility of modern society, are being intensely scrutinized using a range of surveillance techniques. Developing some similar interests to those of Arvidsson, Michael Curry also examines the techniques of market research as these are being used in airline profiling systems. Curry's theoretical and empirical analyses support the proposition that purportedly sophisticated geodemographic systems are actually based largely upon rather simple sets of narratives which incorporate views of the range of mobile behaviors and patterns that are defined as acceptable and suspicious. He also argues that these profiles are designed not to identify the 'trusted' traveler but instead the 'treacherous' traveler. Peter Adey's article examines airports as spaces where surveillance sorting of both objects and actors occurs, rendering airports as filters. He extends his analysis beyond the issues of privacy invasion and categorical discrimination resulting from the sorting of passengers, and uses actor network theory (ANT) to emphasize the need to research the surveillance of non-humans.

The spaces in which the surveillance of mobilities regularly occurs expands beyond those that are arguably hubs of mobility, such as airports, and now extend to any space in which people, objects or words move. Robert Wilson Sweeny reports on an experiment he conducted in a university setting using tactics similar to those of the Surveillance Camera Players to demonstrate the embodiment between techniques of surveillance and panoptic forms of power, and students' responses to such surveillance. His webcam performance and devill.0 webcast to his students allowed him not only to graphically demonstrate the ubiquity of surveillance in the educational space but also to engage students with the issues presented by such surveillance. Trine Fotel and Thyra Uth Thomsen similarly explore questions of surveillance techniques and power relationships, this time in the context of parental monitoring of children's mobility. In addition to comparative and statistical research, the authors analyze qualitative interviews with children aged 10-12 to see how they perceive and cope with their own mobility and its surveillance.

Two final articles investigate the implications of the surveillance of mobility for public policy. Gordon Gow and Mark Ihnat examine the Canadian policy processes that created the system of emergency services for wireless phone users. Their article examines how concerns about privacy rights were addressed in policy development and highlights the importance of providing options for anonymity in the use of wireless technologies. Nicola Green and Sean Smith investigate the implications for regulatory responses for the increasing uncertainty surrounding mobile communications. Based on interviews with regulators and industry stakeholders in the UK, they contend that there are some deep contradictions in the attempt to regulate the processing of mobile data using the concepts and policy instruments of 'data protection'. They especially see a contradiction between the practices associated with the processing of 'traffic data' and the narratives that have been constructed by the courts, by regulators, and by law enforcement agencies. They argue for a new definition of personal data which recognizes the personal nature of all mobile telecommunications information and rejects outmoded distinctions between personal and non-personal data and communications. 


\section{Themes of Surveillance and Mobilities}

\section{What do we mean by 'mobility'? Why foc us on 'mobilities' ?}

As has been noted many times in this journal and other surveillance studies, people no longer exist and live in fixed locations and spaces. Instead people are on the move in their personal, professional, and social spheres. They move from one sphere of their lives to another and within each sphere movement from one activity or place to another, rather than permanence, is likely to be the norm. Castells well captures this in his theory of the space of flows, "our society is constructed around flows: flows of capital, flows of information, flows of technology, flows of organizational interaction, flows of images, sounds, and symbols" (1996: 412). As the articles in this issue illustrate, within these flows there are various forms of mobilities: bodies, cars, suitcases, analog voices, digitized voices, actions, reactions. The list is potentially endless as people move, things associated with people move, and even spaces themselves move. And as these flows assume greater importance, they become important sources of valuable information in themselves. Surveillance in turn has accommodated these changes by also becoming more mobile (Lyon, 2002).

The focus on mobilities and its increasing importance in surveillance and privacy studies accentuates the need to think systematically about mobilities. Mobility, as Peter Adey notes in this issue, is "often viewed in terms of risk to the safe and static containers of space, territory and social order" (502). Mobility is not therefore synonymous with the terms 'location' or 'locatability'. Mobilities involve the transgression of traditionally recognized boundaries and thus challenge conventional categorizations. Roger Clarke has proposed four different meanings when we talk about mobile technologies. First it may mean that devices may be in a different location at any given time from that in which they were at one or more previous times. Second, devices may be mobile in the sense that they may be in any location from which transmission to another device may be possible. Thirdly, it may mean that they are mobile in relation to the movement of the earth's surface, such as when a user of a mobile device is in a plane. And finally, it may mean that devices are designed to be easily and conveniently portable, and to rely on wireless transmission (Clarke, 2003b).

For the sake of some comparisons of the themes in this journal, we propose a rather simple typology of mobility. On the 'what moves' dimension we suggest a three-fold categorization of body (the person), transactions (things the person does either as physical actions or as captured in data), and artefacts (things associated with the individual). This dimension seeks to demonstrate the object(s) of any surveillance. The second dimensions attempts to capture the 'movement itself'. This is a more complicated concept because one is trying to capture something that is by definition in motion, either, as Clarke states, from place A to place B, or from time 1 to time 2 , or in relation to the movement of the earth. Thus we propose that mobility should not be viewed in terms of static categories but instead is more appropriately regarded as a continuum. Movement occurs both within certain fixed spaces and across a range of spaces. Boundaries of spaces may be more or less fixed or, as is increasingly the case, malleable. The second dimension tries to gauge the level or degree of mobility in an effort to demonstrate the depth of surveillance. 
The typology would then allow comparisons of surveillance in different contexts. The articles in this issue provide some illustrative examples.

\section{What a re the goals or purposes of the surveillance of mobilities?}

If surveillance of mobilities is a rather new phenomenon, then a logical question is whether such surveillance is being done for novel purposes. In general the purposes of surveillance systems are fairly similar across systems. Surveillance is a means of determining who is where and what they are doing, either in the physical or virtual world, at a particular point in time (Lyon, 2001 and McCahill, 2002). This is the basic purpose of surveillance and the most common goal of surveillance systems. These systems help answer the questions of who is where, at what point in time, and what are they doing. The tracking of movements for such basic information is a fundamental component in the surveillance systems discussed in all the articles in this issue. The paramount goal of the monitoring of the physical and virtual activities of consumers, travelers, phone users, children and students is to determine their place in space and time. However, this necessary information may not be sufficient. Surveillance systems often operate with multiple purposes.

Second, surveillance systems are also designed to sort people's activities and characteristics for marketing and profiling purposes. This 'panoptic sort' (Gandy, 1993), 'dataveillance' (Clark, 2003a) or 'phenetic fix' (Lyon, 2002; Phillips and Curry, 2002) entails capturing as much information as possible about people's demographic characteristics, preferences, communications, consumer transactions and movements in order to more effectively manipulate them to buy products or behave in preferred ways. Any datum about a person is relevant to the development of these profiles. The increasing capability to capture information about the movements of bodies, transactions and artefacts adds depth and richness to existing profiling systems. And this capability makes possible finer discrimination among people and more accurate manipulation of subjects. This goal of surveillance is prominent in the surveillance of consumers and travelers.

Finally and increasingly surveillance is conducted in order to reduce risk of potential harm and/or liability (Ericson and Haggerty, 1997; Norris and Armstrong, 1999; Ball and Webster, 2003). Crime control concerns and techniques have moved beyond police and security systems and have become more obvious in all social spaces: the workplace, travel hubs, shopping malls, museums, schools. Again the list of spaces and flows of interest is potentially endless. Although exacerbated by the tragic events of $9 / 11$, this goal of surveillance had been increasing prior to that time. CCTV systems are perhaps the most visible example of such surveillance as they are becoming more commonplace in streets, buildings and transportation centers. But this goal is present in a less visible way in many other surveillance systems including the surveillance of children discussed by Fotel and Thomsen in this issue.

If the goals of systems designed to monitor mobilities are similar to those of other surveillance systems then the question remains as to whether there is anything novel or important occurring. To answer this, we turn to a consideration of the consequences of the surveillance of mobilities. 


\section{What are the consequences of the surveillance of mobilities?}

As all surveillance analysts have taken note, over the course of the 20th century surveillance systems have become more ubiquitous to include 'monitoring everyday life' (Lyon, 2001). Workplaces, stores, schools, hospitals are all physical spaces where monitoring occurs. The online world has not been immune to this everyday surveillance as cookies, web-bugs and other technologies capture information on mouse-droppings and click-stream data. One of the most damaging results of the monitoring of everyday life is the further blurring of the boundaries between public and private, between personal and social borders. The surveillance of mobilities defies the contextualization of life: the workplace, store and home are no longer separate places in which one is surveilled but instead each becomes a point on the flow of surveillance. And each of these points is connected to the others, providing a more completely textured rendition of one's everyday life. With the surveillance of mobilities there is potentially no 'hiding'. There is no room to anonymously walk down a street, drive through a neighborhood, or talk on the phone. All these movements and flows are subject to scrutiny, captured, stored, manipulated, and subsequently used for purportedly benevolent or underhandedly sinister purposes. The objects we use (cars, phones, computers, electricity) in turn become tools for surveillance. Actions, conversations, movements are all caught. Movement is not a means of evading surveillance but has become the subject of surveillance.

What will be the consequences of the lack of possibility for unmonitored movement? Might we all just stop? Will we become frozen in catatonic poses as we realize there is no place to hide? These questions are interestingly addressed in Fotel and Thomsen's analysis of the surveillance of children where there is now "adult orchestration of their mobility" (539), in Curry's examination of systems to identify the treacherous traveler, and in Sweeny's devill.0.

The history of surveillance systems would indicate that the most likely consequence of the surveillance of mobilities will be yet more rationalization and control (Giddens, 1985; Beniger, 1986). Gary Marx offers a redefinition of surveillance to take into account the fact that surveillance is no longer focused on suspected persons but is "also applied to contexts (geographical places and spaces, particular time periods, networks, systems and categories of persons) (2002: 10). Such surveillance is more intensive and extensive allowing for finer gradations of what is considered appropriate or deviant. As Peter Adey points out in his article in this issue "particular movements are inscribed with meanings of what is an allowed movement and what is considered suspicious and deviant" (508). And this may lead to more places, such as airports airplanes, being considered 'off-limits' for people exhibiting these movements.

As with other forms of surveillance, the surveillance of mobilities may result in more selfmonitoring as there is an increased awareness that one is under constant, continual and continuous scrutiny. Even if the surveillance is designed not to control but to care and secure, the awareness that one is under scrutiny, or that one might potentially be under scrutiny, can change behaviors in unintended ways. The potential for this having negative unintended consequences is perhaps most apparent in the education setting and with the monitoring of children's movements. At the same time, and as is true with other surveillance systems, there may be increased temptations to, as well as opportunities for, gaming or confronting the surveillance. As Sweeny notes with the Surveillance Camera Players: 
I consciously acknowledge the presence of the camera, altering my behavior accordingly: nervously gawking at the camera, hiding my face, or flipping the bird. Through this performance, I temporarily deflect the gaze of the camera through my embodied practices. (530)

And as surveillance systems collect more information, this leads to more detailed categorization of individuals and then to judgments based on those categorizations, leaving the concept of a unique individual in the dustbin of history. But as Curry suggests, the use of information based on the surveillance of mobilities will lead to collection of ever more information because the judgments that can be made based on place (who belongs in a jetliner, who belongs in this educational space, who drives their car along this highway) are more straightforward than those based on movements. Such information may not necessarily be 'identifiable'. Extrapolations of behavior can be made by knowing the types of people who engage in certain behaviors in certain places at certain times. Our discourses, and our regulatory responses, are still dependent upon outmoded distinctions between what is and is not 'personal data', as Green and Smith demonstrate.

Nevertheless, the surveillance of mobilities requires more detailed data mining to construct narratives of a person's activity, "What is he really doing? Is he a mentally deranged person, desperate to escape his troubles by escaping the country? Is he a criminal...Is he a Cuban émigré, now homesick? Or is he simply a somewhat frazzled businessman?' (485) But surveillance of mobilities assumes that more information and more finely tuned categorization of that information can answer such questions. As Arvidsson points out:

The extraction of surplus value in information capitalism entails the transformation of 'productive life' into 'dead values', like brands or 'content'. This is the main function of the ubiquitous surveillance of the panoptic sort. But this 'branding of life' also tends to lead to its automation. Branded life is programmed life (468).

\section{References}

Beniger, J.R. (1986) The Control Revolution: Technological and Economic Origins of the Information Society. Cambridge, MA: Harvard University Press.

Castells, M. (1996) The Rise of the Network Society. New York: Blackwell.

Clarke, R. (2003a) Dataveillance: Fifteen Years on. Available online at: http://www.anu.edu.au/people/Roger.Clarke/DV/DVNZ03.html

Clarke, R. (2003b) Wireless Transmission and Mobile Technologies. Available online at: http://www.anu.edu.au/people/Roger.Clarke/EC/WMT.html 
Ericson, R.J. and K. Haggerty (1997) Policing the Risk Society. Toronto: University of Toronto Press.

Gandy, O.H. (1993) The Panoptic Sort: A Political Economy of Personal Information. Boulder, CO: Westview Press.

Giddens, A. (1985) The Nation State and Violence. Cambridge: Polity Press

Lyon, D. (2002) Surveillance as Social Sorting: Privacy, Risk, and Digital Discrimination. London and New York: Routledge.

Lyon, D. (2002) Editorial. Surveillance studies: understanding visibility, mobility, and the phonetic fix. Surveillance and Society 1(1): 1-7. Available online at: http://www.surveillance-and-society.org/articles1/editorial.pdf

McCahill, M. (2002) The Surveillance Web: The Rise of CCTV in an English City. Collompton: Willan.

Norris, C. and G. Armstrong (1999) The Maximum Surveillance Society: The Rise of CCTV. Oxford, UK: Berry.

Phillips, D. and M. Curry (2002) Privacy and the phenetic urge: geodemographics and the changing spatiality of local practice. In D. Lyon (ed) Surveillance and Social Sorting: Privacy, Risk and Digital Discrimination. London and New York: Routledge, 137152. 